\title{
Environment monitoring and assessment in GNPS
}

\author{
Zhang Dong Guo
}

Guangdong Daya Bay Nuclear Power Station (GNPS), Shenzhen 518124, China

\begin{abstract}
Two PWR units at Guangdong Daya Bay Nuclear Power Station (GNPS) in China have been putting into commercial operation in succession since early 1994 . The other two units now are under construction face. To monitor and assess the environment impact caused by radioactive effluents released during the normal operation of the plant, GNPS has developed an Environmental Radiation Monitoring Program (ERMP) based on the related China environment protection regulations currently in force, and also taken into account the experience feedback from French nuclear power stations, Furthermore it was approved by the National Environment Protection Administration (NEPA)before being implemented. This article gives a brief introduction on the program carried out in GNPS.
\end{abstract}

\section{Environmental Radiation Monitoring Program (ERMP) in GNPS}

In GNPS the ERMP is divided into two parts: The first part of the ERMP, known as the Background Radiation Monitoring Program (BRMP), was carried out before the commercial operation of GNPS. The second part of the ERMP has been carried out since the first core loading of GNPS in July of 1993.

\subsection{Background Radiation Monitoring Program (BRMP)}

The BRMP should be implemented at least two years before the operation of GNPS according to China environment protection regulations. To meet this requirement, the BRMP was carried out for two periods from July of 1988 to November of 1989,from December of 1990 to March of 1992 .

\section{The objective of the BRMP is:}

* To identify critical radioactive nuclides that are likely to be released into environment by the GNPS operation, critical pathway and critical population group should also be identified through the implementation of the BRMP.

* To establish the baseline radiation level in the GNPS surrounding areas before operation of the plant.

* To check and validate monitoring methods and procedures to be used during plant operation as well as training of staff.

The program is comprised of territory - wide monitoring of the ambient gamma radiation level, and measurements of the activity concentration of alpha, beta and gamma emitting radioactive nuclides in various types of environmental samples.

The report of the BRMP, published in November of 1992 was reviewed by experts coming from different national environmental protection agencies, and was finally submitted to the NEPA. 


\section{Main conclusions drawn from the report are as follows}

* The areas around GNPS site, the cosmic radiation dose rate is about $29.5 \mathrm{nGy} / \mathrm{h}$; average gamma dose rates for fields, roads and indoor are $99.8 \mathrm{nGy} / \mathrm{h} \pm 19.8,94.0 \mathrm{nGy} / \mathrm{h} \pm 10.9$ and $145 \mathrm{nGy} / \mathrm{h} \pm 12.8$ respectively, which are superior to the average value of 26 cities in China $(61.2 \mathrm{nGy} / \mathrm{h}, 57.4 \mathrm{nGy} / \mathrm{h}$ and $97.7 \mathrm{nGy} / \mathrm{h}$ for these three items respectively). This coincides with the fact that the earth surface geological structure in Guangdong province is mainly constituted of granite;

* Cumulated Gamma doses over the exposed periods at 36 positions cover a range from $33.4 \mathrm{uGy} / \mathrm{month}$ to $145 \mathrm{uGy} /$ month.

* Most of the radioactivity found in the various types of environment samples at Daya Bay area originates from natural radioactive nuclides;

* Sr-90, H-3, and Cs-137 concentrations are very low; concentration levels of artificial radioactive nuclides are in agreement with global fallout from the past nuclear bomb atmospheric tests in the $20 \mathrm{~N}$ latitudes.

\subsection{Environment Radiation Monitoring Program (ERMP) during normal operation of GNPS.}

The second part of the ERMP, known as the ERMP after normal operation of GNPS, has been carried out since July of 1993.

\section{ERMP during normal operation of the GNPS was designed :}

* To evaluate the effectiveness of management of radioactive wastes and control of radioactive effluents released by GNPS;

* To determine any possible long term variation of radioactive nuclide concentrations and ambient radiation levels in environmental media;

* To evaluate the possible imposed exposure dose on public in particular on critical population group;

* To explore the dispersion and transport law of radioactive nuclides from the effluents in the environment and to check the validity of environmental assessment models;

Principle for determination of monitoring areas and locations

In accordance with the national environment protection regulations, in GNPS, the monitoring of ambient gamma radiation takes the areas with a radius of $50 \mathrm{~km}$ around the plant, other items with a radius of $20 \mathrm{~km}$, the land and waters with a radius of $10 \mathrm{~km}$ from the plant is considered as the major monitoring area. Penceng, a village, $3.8 \mathrm{~km}$ away from GNPS at leeward direction of predominant wind direction (west) is considered as the critical monitoring point, Huidong, $48 \mathrm{~km}$ away from GNPS at minimal wind direction (NNE) has been chosen as a reference monitoring point for comparison.

Marine monitoring points are distributed within the half - closed west Daya Bay waters.

Particular consideration for deployment of monitoring points is given to: the living areas for critical population group; the leeward areas at prevailing wind direction; in agreement with the positions chosen during background investigation; the sea product aquiculture within Daya Bay;

Monitoring pathway

To detect artificial radioactive nuclides released by the operation of the GNPS, three major exposure pathways, atmospheric pathway, terrestrial pathway and aquatic pathway are monitored. 
* The ambient gamma radiation levels are continuously monitored by the plant radiation monitoring systems, consisting of 7 fixed monitoring stations. Ambient gamma dose rates at each station are monitored continuously by a silicon semiconductor detector, the data are transmitted to the plant lab once every five minutes. The ambient gamma dose-rates in roads, fields, indoors are also monitored with portable gamma dose rate meters at the selected positions once every quarter.

* Ambient cumulated gamma doses, averaged over a longer period are measured by a thermoluminescent dosimeter (TLD) with about 40 fixed monitoring positions throughout the areas within $50 \mathrm{~km}$ from the plant. The TLDs are read and replaced once every quarter.

* Air samples, including atmospheric paticulates and gaseous iodine are collected continuously on paper filters and activated carbon cartridges with air sampling pumps at 3 fixed positions.

Terrestrial pathway

The ingestion of radioactive nuclides in foodstuff is one of the pathways leading to internal retention and coniributes to human exposure from natural and man-made sources.

To monitor the terrestrial pathway, the samples of various types of foodstuff typical to the diet of the local population or produced in large quantities for market sailing are collected at distribution points within a radius $20 \mathrm{~km}$ from the plant, the samples for the purpose of comparison are collected at a point $50 \mathrm{~km}$ from the plant. The types of foodstuff consist of rice, vegetable, chicken, lychee and orange.

Samples of soil are collected at 6 fixed points once every six months for studying either total deposition or the availability of radioactive nuclides to crops grown in cultivated agricultural land. The samples of grass and pine leaf are also collected on site and at the plant boundary once every six months.

\section{Aquatic pathway}

Samples collected in the aquatic pathway during the plant operation period, consist of drinking water, reservoir water, underground water, rainwater, sea water, aquatic foodstuff, seaweed and sediment. Samples of drinking water are collected from the GNPS/LNPS site and Penchen from distribution taps once every month. Samples of reservoir water are collected from 3 reservoirs situated near the plant. Samples of underground water are collected at the GNPS site from 6 monitoring wells. Samples of rainwater are collected on site at five locations, the sampling frequencies of underground water, reservoir water and rain water are also once every month. Seawater samples are collected from the half closed west Daya Bay at 3 points once every four months. Seawater samples taken from discharge channel are collected every day by an automatic sampling device.

Samples of aquatic foodstuff consist of freshwater fish, marine fish, shellfish, shrimp, pearl oyster, squid. The samples are collected once every six months either from local fisherman or from breeding farms in Daya Bay area. Seaweeds as a marine monitoring indicator are collected at 20 points in Daya Bay once every year.

Intertidal sediments are sampled at three areas along the coast of west Daya Bay, seabed sediments are sampled at 3 areas within Daya Bay, of both sampling frequencies are also once every six months.

\section{The main environment monitoring facilities of the GNPS}

\subsection{Atmospheric radiation monitoring stations}

Three gamma radiation monitoring stations named $\mathrm{AS} 1, \mathrm{AS} 2, \mathrm{AS} 3$ are situated to the west, northwest and 
east of the plant stack respectively at a distance of approximately $1000 \mathrm{~m}$. Each of them is equipped with: * a continuous monitor of gamma radiation, measuring range from $1.0 \mathrm{E}-8 \mathrm{~Gy} / \mathrm{h}$ to $1 \mathrm{~Gy} / \mathrm{h}$;

* Radio transmitter-receiver.

* An atmospheric particulate and gaseous iodine sampling device;

* Each monitoring station is equipped with a rain water collector;

Four monitoring stations named BS1, BS2, BS3 and BS4 are situated at about 5-10km away from the site:

* BS1 to the northwest of GNPS, at Bagang;

* BS2 to the northeast of GNPS, at Lingao;

* BS3 to the southwest of GNPS, near Shuitou;

* BS4 to the west of GNPS, at Dapeng

Each of them is equipped with

* a continuous monitoring detector of gamma radiation measuring range $10 \mathrm{E}-8 \mathrm{~Gy} / \mathrm{h}-1 \mathrm{~Gy} / \mathrm{h}$

* a radio transmitter- receiver

The measuring signals and alarm signals of the continuous monitor of gamma radiation from different monitoring stations are transmitted in proper order via radio transmitter-receiver to the ceniral computer system, after being processed the signals will be recorded and displayed at plant headquarter.

\subsection{Liquid discharge monitoring station}

The liquid discharge monitoring station is situated by the middle of discharge channel. The sampling device of this station automatically takes seawater from the discharge channel, then a hydrocollector distributes the seawater (drop by drop) to 24 flasks with approximately 2 liters capacity, the samples are representative of one hour sampling.

\subsection{Meteorological station}

The meteorological station is situated under the leeward prevailing winds at distance approximately $700 \mathrm{~m}$ to the west of the GNPS plant stack.

The station consists of following equipment;

a $80 \mathrm{~m}$ meteorological tower (pylon), a standard ground meteorological station, an automatic data acquisition station and a data processing center.

* The meteorological tower (pylon) is equipped with temperature and wind sensors at $10 \mathrm{~m}$ and $80 \mathrm{~m}$ above ground level.

* Ground meteorological station located at the foot of the pylon is equipped with a temperature probe, a hygrometer, a rain gauge and an automatic recording barometer.

* Automatic data acquisition station (ADAS) is equipped with a static memory capable of storing.

* Data processing center is located in site laboratory and equipped with printers, operators, dialog terminals, graphic recorder and distributed susceptor. Alarm signal can be transmitted to main control room; meteorological parameters (wind direction, wind speed, temperature) can be received in main 
control room, EG building (emergency center) and BX building (administrative building of operation department).

\subsection{Environment laboratory:}

Environment laboratory is situated southwest to the GNPS site about $1 \mathrm{~km}$ away.

After samples are collected and delivered to the environment laboratory, they are subject to sample treatment using either physical or chemical methods, followed by radioactivity measurement using radiological analytical methods, each sample depending on the sample type, would go through one or more of the following analysis processes;

* gamma spectrometry for detecting and measuring the activity concentration of gamma emitting radioactive nuclides.

* liquid scintillation counting to determine the activity concentration of tritium.

* radiochemical analysis plus global beta measurement to determine the activity concentration of strontium-90.

* global alpha and beta measurement to determine the global alpha and beta activity of various environment samples, including atmospheric particulate, soil, sediment, water and terrestrial and marine life.

* Atomic absorption measurement to analyze the activity concentration of potassium-40

All the monitoring methods used for detecting and measuring environmental samples and their lower limits of detection (LLD) satisfy the requirement stipulated in the related national standards.

To acquire representative, accurate, precise and comparable analytical data during the implementation of the ERMP, the activities of analytical quality control have been carried out periodically with following methods.

Participating in an inter-laboratory comparison practice with other laboratories even with IAEA.

Periodic calibration of measurement systems with standards of radioactive nuclides

The status of equipment routine checking

With the good practice of above activities, GNPS/LNPS environment laboratory assures the analytical quality of the ERMP.

\section{Results of the ERMP (Environment Radiation Monitoring Program)}

The ERMP has been carried out since July of 1993, the main results obtained during this period are as follows.

- The results of gamma dose rates recorded at 7 continuously monitoring stations report a range from $0.1 \mathrm{uGy} / \mathrm{h}$ to $0.19 \mathrm{uGy} / \mathrm{h}$. The cumulated Gamma doses over the exposed periods at 36 positions report a range from $28.5 \mathrm{uGy} / \mathrm{month}$ to $150 \mathrm{uGy} /$ month that is in agreement with the range from $33.4 \mathrm{uGy} / \mathrm{month}$ to $145 \mathrm{uGy} / \mathrm{month}$, obtained during background investigation. Spatial variation is generally caused by the difference in geological composition of the soil rock and the building material, temporal variations are generally caused by changes in meteorological conditions such as rainfall, wind and barometric pressure. 
- The results of total beta measurement for atmospheric particulate show that variations exist obviously with season changes those in spring and winter are quite higher than those in summer and autumn, the results cover a range from $0.44 \mathrm{E}-3 \mathrm{~Bq} / \mathrm{m} 3$ to $6.45 \mathrm{E}-3 \mathrm{~Bq} / \mathrm{m} 3$, this is in agreement with those during the background investigation. No measurable amount of artificial gamma emitting radioactive nuclides was found in samples of atmospheric particulate and gaseous Iodine with Gamma spectrometric analysis.

- The natural and artificial radioactive nuclide concentrations in the samples of soil, sediment of reservoirs, terrestrial life, present the same levels as background levels.

- The concentrations o natural and artificial radioactive nuclides in samples of rainwater, drinking water, water of reservoirs still remain at background levels.

- The concentration levels of the activated radioactive nuclides in the samples of marine life, for example, ${ }^{110 \mathrm{~m}} \mathrm{Ag}$ are much lower than the anticipated concentration levels estimated in GNPS Environment Impact Report" (project design face) those was verified and approved by NEPA.

\section{Conclusion}

Environment monitoring results show that the ambient gamma radiation levels as measured by the continuously monitoring stations and TLDs are still representative of the background radiation levels. The concentration levels of natural and artificial radioactive nuclides in the samples of air, terrestrial life, freshwater, soil and sediments of reservoirs still remain at background levels, only a trace of radioactive nuclides are found in the samples of sediment, shell fish, seaweed but the concentration levels of those are much lower than the levels estimated in the feasibility study report thus no noticeable change of the environment radioactivity level has been observed after operation of the GNPS in the Daya Bay area. 